Article

\title{
Social Connectedness in Physical Isolation: Online Teaching Practices That Support Under-Represented Undergraduate Students' Feelings of Belonging and Engagement in STEM
}

\author{
Ian Thacker ${ }^{1, *(\mathbb{D})}$, Viviane Seyranian ${ }^{2}$, Alex Madva ${ }^{3}$, Nicole T. Duong ${ }^{4}$ iD and Paul Beardsley ${ }^{5}$ \\ 1 Department of Educational Psychology, The University of Texas at San Antonio, San Antonio, TX 78207, USA \\ 2 Department of Psychology, California State Polytechnic University, Pomona, CA 91768, USA; \\ vseyranian@cpp.edu \\ 3 Department of Philosophy, California State Polytechnic University, Pomona, CA 91768, USA; \\ ammadva@cpp.edu \\ 4 Divison of Behavioral \& Organizational Sciences, Claremont Graduate University, Claremont, CA 91711, USA; \\ nicole.duong@cgu.edu \\ 5 Center for Excellence in Mathematics and Science Teaching, Biological Sciences Department, California State \\ Polytechnic University, Pomona, CA 91768, USA; pmbeardsley@cpp.edu \\ * Correspondence: ian.thacker@utsa.edu
}

\section{check for}

updates

Citation: Thacker, I.; Seyranian, V.; Madva, A.; Duong, N.T.; Beardsley, P. Social Connectedness in Physical Isolation: Online Teaching Practices That Support Under-Represented Undergraduate Students' Feelings of Belonging and Engagement in STEM. Educ. Sci. 2022, 12, 61. https:// doi.org/10.3390/educsci12020061

Academic Editor: Kelum A.

A. Gamage

Received: 15 December 2021

Accepted: 10 January 2022

Published: 18 January 2022

Publisher's Note: MDPI stays neutral with regard to jurisdictional claims in published maps and institutional affiliations.

Copyright: (C) 2022 by the authors. Licensee MDPI, Basel, Switzerland. This article is an open access article distributed under the terms and conditions of the Creative Commons Attribution (CC BY) license (https:// creativecommons.org/licenses/by/ $4.0 /)$.

\begin{abstract}
The COVID-19 outbreak spurred unplanned closures and transitions to online classes. Physical environments that once fostered social interaction and community were rendered inactive. We conducted interviews and administered surveys to examine undergraduate STEM students' feelings of belonging and engagement while in physical isolation, and identified online teaching modes associated with these feelings. Surveys from a racially diverse group of 43 undergraduate students at a Hispanic Serving Institution (HSI) revealed that interactive synchronous instruction was positively associated with feelings of interest and belonging, particularly for students of color, while noninteractive instruction reduced social belonging, but was related to more cognitive engagement. Small group and one-on-one interviews with 23 of these students suggest that students derived feelings of connectedness from their instructors, peers, and prior experiences and relied on their sense of competency to motivate themselves in the course and feel a sense of belonging. Two embedded cases of students in physics classrooms are compared to highlight the range of student feelings of connectedness and competency during the lockdown. Findings reaffirm that social interaction tends to support belonging and engagement, particularly for under-represented (Black or African American and Hispanic) racial groups in STEM. STEM instructors who aim to support feelings of belonging and engagement in virtual learning environments should consider increasing opportunities for studentstudent and student-teacher interactions, as well as taking a flexible approach that validates and integrates student voice into instruction. Future research is needed to further explore the themes of relatedness and competency that emerged as aspects of course belonging.
\end{abstract}

Keywords: COVID-19; online instruction; belongingness; engagement; STEM education

The COVID-19 outbreak caused unprecedented disruptions to educational institutions, including temporary closures and unplanned switches to online classes during the spring of 2020 [1], which disproportionately affected women and students of color [2-4]. These rapid changes led to the closure of physical environments that foster social interactions and learning communities. Collaborative learning environments such as laboratories, libraries, maker spaces, tutoring centers, and physical spaces that support office hours and study groups were rendered inactive, potentially dissolving associated social structures and learning communities that are crucial for learning.

Interpersonal engagement is considered central in the sociocultural learning theory [5-7] and fulfills basic psychological needs to feel connected and to belong in a learning community [8]. This engagement is particularly important for supporting women 
and students of color to forge STEM identities [9] and persist in STEM fields [10-12]. Schools and educators across the world undertook efforts to adapt to rapidly changing circumstances of COVID-19 and to support their students through academic and life challenges [1]. However, little empirical research has studied the specific instructional methods that instructors used to adapt to the ever-changing circumstances of the pandemic and how these practices affected under-represented groups of students' belonging to critical transition classes in STEM. Understanding how to better support students' sense of belonging and community online is key to their retention and matriculation in STEM.

Feelings of inclusion and belonging are a fundamental psychological need and are essential for belonging and engagement, particularly for under-represented racial/ethnic and gender groups in STEM [11,13-16]. A sense of belonging among women in virtual computer science undergraduate classrooms can mitigate the negative impacts of apparent stereotypes [17], and interpersonal interaction in virtual environments can support feelings of belonging and positive emotion [18]. However, much of this prior research was in contexts where faculty and students had willingly chosen virtual environments for STEM instruction, where virtual instruction could be readily supplemented with physical learning spaces (e.g., libraries and laboratory settings). It is also important to discern the extent to which belonging is important for under-represented racial/ethnic groups, particularly in a context of transition from in-person learning to mandated physical isolation. The purpose of this study is to identify online teaching practices that undergraduate STEM instructors employed after the transition to mandated online instruction during the COVID19 pandemic and to explore their impacts on students' sense of belonging and engagement.

In the following, we summarize the theory on the role of students' sense of belonging, community, and engagement in supporting retention, matriculation in STEM, and particularly for students of color. We also summarize literature on how to design online learning environments that support such a sense of community. Then, we present a multi-method study investigating the impacts of different online learning practices on undergraduate students' motivation and engagement in STEM at a Hispanic Serving Institution (HSI).

\section{Theoretical Framework}

To examine the influence of different modes of distance instruction on student belonging and engagement, we drew from the literature on belonging from the Self-Determination Theory and from Kahu's sociocultural model of student engagement [19].

\subsection{Self-Determination Theory and the Need to Belong}

The Self-Determination Theory [20] proposes that students are more likely to engage, learn, and grow when they are able to determine choices that affect key aspects of their lives. People are most likely to grow when three fundamental psychological needs are met. Students need to feel (a) competent to meet and master challenges of their schoolwork, (b) autonomous insofar as their actions stem from their own interests and values, and (c) a sense of social belonging and relatedness in the classroom, academic community, as well as a general connection to others [21]. Once these needs are met, students' academic performance reflects an internal locus of causality. They take ownership of their learning, view their academic behaviors as stemming from their own volition, and develop an intrinsic motivation and engagement [22].

Of the three fundamental psychological needs in the Self-Determination Theory, the need for relatedness is most central to this study. Relatedness is the need to feel connected with others, including with instructors and other students, and to feel general belonging $[8,20,22-24]$. Belonging helps students internalize the goals and values of the instructor and the community and leads them to view extrinsically rewarded tasks (e.g., completing homework for a grade) as more personally meaningful (e.g., performing homework because it is important and aligns with their goals and values [25]). Feelings of belonging and academic engagement can be supported through teacher-student rela- 
tionships [26,27], and relationships with peers [22] and parents [28]. Further, students' sense of belonging to their institution and classroom community is a key factor that motivates them to pursue and persist through undergraduate STEM programs, and is associated with achievement and motivational outcomes, particularly for women and students of color [24,29-37].

Nevertheless, some students feel out of place in some academic settings. Underrepresented racial/ethnic groups of students can be stigmatized in some academic settings, where they are caused to feel that they do not "fit in" [14]. Walton and Cohen found that motivation and achievement of students of color were disproportionately impacted by doubts seeded about whether they belong in a field of study [38].

Doubts of belonging may have been exasperated by the sudden transition to online learning during the early stages of the COVID-19 pandemic. Under-represented racial groups in STEM may have been particularly susceptible to feelings of exclusion as a result of relying exclusively on platforms created by instructors and universities rather than having opportunities to connect with others face-to-face in physical situations and on their own terms. Students of color may also have disparate access to digital learning resources at home (e.g., internet, computer access, and access to quiet and private spaces [39]), which may further exacerbate a lack of belonging. One of the aims of this research was to examine how students' sense of belonging was affected by the virtual transition online, with particular attention paid to under-represented racial groups in STEM.

\subsection{Engagement}

Academic engagement can be defined in multiple ways, often referring to how students act, feel, and think. It is a multidimensional construct that consists of behavioral, affective, cognitive, and social dimensions $[19,40,41]$. According to research summarized by Fredricks and colleagues (2004), behavioral engagement can be defined as an individuals involvement in academic activities [41]. It is operationalized as behavioral participation and time spent on academic activities (e.g., "time on-task"). Affective engagement refers to positive and negative reactions to academic situations, including students' feelings about their peers and instructors, and their attitudes about and interest in the course content. Cognitive engagement is students' investment in their own learning and involves a willingness to expend effort and attention to make sense of complex topics. These three framings of engagement are distinct yet interrelated, and dynamically linked with social and cultural context and broadly tend to predict positive learning and motivational outcomes [41]. To incorporate interrelations between multiple forms of engagement and to frame our study in terms of instructional modes that support this engagement, social interaction, and belonging, we drew from Kahu's (2013) sociocultural model of engagement [14].

Kahu (2013) explains how learning environments can be designed to enhance affective, cognitive, and behavioral engagement and belonging by supporting interpersonal relationships between students and teachers [14]. This conceptual framework incorporates elements of multiple framings of engagement to show how interrelationships between students and faculty can support multiple dimensions of engagement: affective engagement (interest and belonging), cognitive engagement (characterized by regulation and deep learning), and behavioral engagement (time, effort, interaction, and participation), all of which are thought to support academic achievement, social well-being, long-term persistence and retention, and personal growth. Furthermore, Kahu suggests that this process is situated within the larger social and political environment, which may include economic or cultural pressures. Drawing from this model, we distinguished between affective, cognitive, and behavioral engagement outcomes and adjusted quantitative models for contextual impacts and pressures stemming from the COVID-19 pandemic.

\subsection{Online Practices That Support Interaction and Engagement}

Prior empirical research shows that increased opportunities for social interaction in online STEM learning environments leads to positive engagement outcomes, whether those 
interactions occurred asynchronously or synchronously. A review of the distance learning literature shows that asynchronous online interactions (e.g., using discussion boards) can encourage university students to contemplate content more deeply before connecting with the learning community and is positively associated with cognitive engagement [42]. In comparison, synchronous interactions (e.g., via live-streamed instruction or breakout groups) can allow for more instantaneous feedback from instructors and peers, more comfortable and natural interactions, and is positively associated with behavioral and affective engagement outcomes [42,43].

Concerning STEM courses specifically, Jeong and colleagues (2019) conducted a metanalysis of 143 experimental and quasi-experimental studies revealing that collaborative online learning environments in STEM had an average effect size of $g=0.55$ when compared across a variety of cognitive, affective, and behavioral outcomes [44]. These effects were similar across different modes of social collaboration, whether face-to-face $(g=0.51, n=146)$, synchronous ( $\mathrm{g}=0.51, \mathrm{n}=75)$, or asynchronous $(\mathrm{g}=0.50, \mathrm{n}=73$ ). The average effect was positive for undergraduate populations ( $g=0.45, \mathrm{n}=94)$. Given these findings, we expected that the use of online instructional techniques that emphasize social interaction-such as synchronous or asynchronous discussion, synchronous chat, or breakout groups-would facilitate social relationships and a sense of belonging when compared with non-interactive slide show presentations, individual work, or live presentations that limit interpersonal interactions [18,44]. Although these findings are informative in highlighting the importance of interpersonal interaction in online learning, they focused exclusively on online learning environments prior to the COVID-19 pandemic - a time when interpersonal connections could be readily reinforced with physical infrastructure, and virtual learning was not mandated.

One of the aims of the current study was to understand how engagement might be maintained and fostered by instructors in a time of forced mass transition to online learning and physical distancing. Towards this end, we conducted online group interviews and surveys with undergraduate students taking math-intensive STEM courses shortly after all courses transitioned online and a local lockdown was instituted during the COVID-19 pandemic.

\subsection{Current Study}

We sought to better understand relationships between virtual instructional practices in STEM and student engagement and belonging during the pandemic. We collected both qualitative and quantitative data from a diverse group of undergraduate students enrolled in math-intensive STEM courses over the span of three weeks in April and May of 2020 during the early stages of the pandemic. We had three research questions which were addressed separately by quantitative and qualitative data.

\subsubsection{Research Questions Addressed with Quantitative Data}

1. To what extent are student-reported online teaching methods related to their sense of belonging and affective/cognitive engagement in STEM during times of crises?

2. Are the impacts of these teaching methods different for ethnically/racially underrepresented students?

\subsubsection{Research Question Addressed with Qualitative Data}

3. Which online social interactions do students experience as supporting or hindering their belonging and engagement?

To answer these research questions, we conducted a two-part multi-methods study, simultaneously collected with students enrolled in mathematics-intensive STEM courses at a large HSI. Students volunteered to participate in a virtual group interview session that involved two parts-(a) a group interview (qualitative data), followed by (b) a survey with quantitative measures. Quantitative survey data were collected to allow us to examine relationships between online teaching practices and student belonging and engagement in STEM. Qualitative data were collected to provide a deeper and richer understanding 
of why certain virtual practices fared better than others in this unusual context [45-47], and so we probed students during in-depth group interviews on their STEM learning experiences and belonging and engagement. All quantitative and qualitative data were collected toward the end of the spring semester (24 April-21 May) of 2020, five weeks after the university transitioned to online learning (18 March 2020). Note that, because the unanticipated transition from in-person to virtual instruction occurred mid-semester, students did not know ahead of time whether they would be registering for a course that would eventually be taught synchronously or asynchronously. Course format was at the discretion of the instructor after the online transition.

\section{Methods}

\subsection{Participants}

Participants for this study were recruited from a pool of students who had previously taken or were currently taking either Calculus II or a calculus-based Newtonian physics course. Students from these courses were targeted for the study because disaggregated institutional data from 2011 to 2017 revealed that two series taken by engineering and science students had high failure rates and achievement gaps. Data from the 2018 to 2019 school year suggested the Calculus-based Physics and Calculus II courses had 15\% and $29 \%$ failure rates, respectively. As such, these courses were identified as first-year critical transition courses. Course GPA gaps also existed for under-represented minority students (16\% Physics, $18 \%$ for Calculus II), first-generation students (14\% Physics, $10 \%$ for Calculus II), Pell-eligible students (14\% Physics, 10\% Calculus), and women in Physics (90\%).

Participants were contacted through email and invited to participate in small virtual group interviews. At the end of each group interview, students completed a survey about their STEM courses during COVID-19. Students were compensated with USD 50 of funding to their on-campus account. They were also provided with links to counseling, housing, and financial campus resources. Students from the same participant pool were also given the option to complete the survey without participating in group interviews through their course website without compensation.

\subsection{Survey}

Survey participants were $N=43$ undergraduate students. Students' reported gender, age, and race/ethnicity representative of the university. Students had completed an average of 2.1 years as an undergraduate (see Table 1 for descriptive statistics for student characteristics). We ran a post hoc sensitivity analysis using G-POWER to assess the minimum detectable effect for our most demanding hypothesis with respect to sample size, which revealed that we were able to detect an effect size of 0.5 for a linear multiple regression model with power of 0.8 , alpha level of 0.005 , and 14 predictors total [48]. For our less demanding models that included seven predictors, the minimum detectable effect size was 0.3 .

Table 1. Descriptive statistics for student characteristics $(N=43)$.

\begin{tabular}{|c|c|c|c|c|c|c|c|c|}
\hline Variable & $\mathbf{n}$ & $\%$ & $\mathbf{M}$ & SD & Min & Med & Max & $\alpha$ \\
\hline \multicolumn{9}{|l|}{ Student Characteristics } \\
\hline Hispanic, Latino, or Spanish in origin & 43 & $40 \%$ & & & & & & \\
\hline Asian (Japanese, Chinese, Vietnamese) & 43 & $30 \%$ & & & & & & \\
\hline White (English, Russian, Scandinavian) & 43 & $28 \%$ & & & & & & \\
\hline $\begin{array}{l}\text { Black or African American (e.g., Haitian, Ethiopian, } \\
\text { South African) }\end{array}$ & 43 & $5 \%$ & & & & & & \\
\hline Female & 43 & $42 \%$ & & & & & & \\
\hline Male & 43 & $56 \%$ & & & & & & \\
\hline Other gender/Prefer not to say & 43 & $2 \%$ & & & & & & \\
\hline Survey Time (minutes) & 43 & & 29.1 & 8.75 & 12.1 & 29.4 & 56.7 & \\
\hline Age & 43 & & 19.8 & 2.2 & 18 & 19 & 30 & \\
\hline Year of Study & 43 & & 2.1 & 1.4 & 1 & 2 & 7 & \\
\hline
\end{tabular}


Table 1. Cont.

\begin{tabular}{|c|c|c|c|c|c|c|c|c|}
\hline Variable & $\mathbf{n}$ & $\%$ & $\mathbf{M}$ & SD & Min & Med & Max & $\alpha$ \\
\hline \multicolumn{9}{|c|}{ Reported Frequency of Instructional Method } \\
\hline Prerecorded lecture & 43 & & 2.8 & 1.6 & 1 & 2 & 6 & \\
\hline Noninteractive live lecture & 43 & & 2.8 & 1.6 & 1 & 3 & 6 & \\
\hline Interactive live lecture & 43 & & 2.9 & 1.7 & 1 & 3 & 6 & \\
\hline Discussion & 43 & & 1.7 & 0.9 & 1 & 1 & 5 & \\
\hline Breakout groups & 43 & & 1.9 & 0.9 & 1 & 2 & 5 & \\
\hline Individual work & 43 & & 3.8 & 2.1 & 1 & 5 & 6 & \\
\hline \multicolumn{9}{|l|}{ Motivation Scales } \\
\hline Belonging since COVID-19 & 34 & & 4.9 & 0.9 & 2.6 & 4.8 & 6.8 & 0.90 \\
\hline Positive emotion & 43 & & 2.9 & 1.4 & 0.9 & 2.6 & 6 & 0.93 \\
\hline Negative emotion & 42 & & 2.5 & 1.6 & 1 & 1.8 & 7 & 0.88 \\
\hline Perceptions of teaching quality & 43 & & 5.3 & 1.4 & 1 & 5.3 & 8 & 0.96 \\
\hline Cognitive engagement & 43 & & 4.4 & 1.0 & 1.6 & 4.6 & 6.1 & 0.86 \\
\hline Interest in STEM & 42 & & 4.9 & 1.7 & 1 & 5 & 7 & 0.89 \\
\hline \multicolumn{9}{|l|}{ COVID-19 Threat } \\
\hline Concern about COVID-19 & 43 & & 4.8 & 1.4 & 1 & 4.8 & 7 & 0.90 \\
\hline Financial impacts & 43 & & 4.5 & 1.9 & 1 & 4.5 & 7 & 0.87 \\
\hline Impacts on resources & 43 & & 3.0 & 1.5 & 1 & 3.5 & 6.5 & 0.71 \\
\hline Psychological impacts & 43 & & 3.0 & 1.5 & 1 & 3.5 & 6.5 & 0.71 \\
\hline Mean of COVID-19 Threat Variables & 43 & & 4.3 & 1.2 & 2.3 & 4.4 & 6.6 & 0.85 \\
\hline
\end{tabular}

Student surveys contained ten scales, seven of which are presented in detail in the current study. Two scales were used in our models as explanatory variables and five were included as separate response variables. The mean time to complete the survey was $29 \mathrm{~min}$. All survey materials are included in the Supplemental Materials.

\subsubsection{Explanatory Variables}

Online teaching methods. Students reported the percentage of time that their Math/Physics or STEM class sessions were delivered via the following instructional modes after the virtual online transition: Pre-recorded lecture (e.g., PowerPoint voiceover), non-interactive lecture (e.g., live Zoom lecture where mainly the instructor is talking), interactive lecture (e.g., live lecture that includes polls, chats, or questions), whole-class discussion, small group work or discussion in breakout rooms, and individual work. Responses were reported on a five-point interval scale $(1=0-20 \% ; 2=20-40 \% ; 3=40-60 \%$; $4=60-80 \% ; 5=80-100 \%$ of the time). Items were adapted from Wieman Group (2020) [49].

COVID-19 threat and impacts. Basic needs impacted by COVID-19 were measured using the Coronavirus Threat and Impacts Questionnaire [50] consisting of ten items capturing concern, financial impacts, resource impacts, and psychological impacts. Responses were provided on an agreement scale that ranged from $1=$ Strongly Disagree to $7=$ Strongly Agree (from hereon, called an agreement scale). The scale was reliable in this study at conventional levels $(\alpha=0.85)$.

\subsubsection{Response Variables}

Belonging. Course belonging was measured after the transition to online teaching using an adapted version of the Psychological Sense of School Membership scale (PSSM) [32]. This scale consisted of 21 items that prompted students to report feelings of connectedness in their Math/Physics course or STEM courses on a scale from $1=$ not at all true to $7=$ very true $(\alpha=0.88)$.

Positive and Negative Emotion. Emotions were measured using a modified version of the differential emotions scale [51]. The 22 item scale prompted students to report the frequency of emotions experienced during their STEM classes ranging from negative (10 items; $\alpha=0.88$ ) to positive (12 items; $\alpha=0.93)$. Responses ranged from $1=$ never to 7 = always. 
STEM interest. Interest was measured using two items (e.g., "My STEM course fascinates me") adapted from Hulleman et al. (2010) on a seven-point agreement scale $(\alpha=0.89)$ [52].

Cognitive engagement. Cognitive engagement was measured using the 16-item scale developed by Greene and Miller (1996) that prompted students to report their levels of cognitive engagement (e.g., "I compare and contrast different concepts") on a seven-point agreement scale $(\alpha=0.86)$ [53].

Perceptions of instructor quality. The Collegiate Teaching Proficiency Scale [54] tapped into students' perceptions of teaching quality with 20 items (e.g., "my instructor motivates students to learn online") on a seven-point agreement scale $(\alpha=0.96)$.

\subsection{Group Interviews}

A total of $n=21$ students who completed the survey also participated in small group interviews. These students were similar demographically to the students who completed the survey (see Table 1 for descriptive statistics of student characteristics).

Students participated in semi-structured interviews on Zoom in groups of one to three from 24 April to 8 May 2020. Small groups and individual interviews (1 to 3 interviewees) were conducted to keep discussions manageable, short, and to maximize interactivity and engagement among all participants [55]. Small group interviews also allowed students enough time to share their individual perspectives and build upon one another's experiences [56]. All interviews were proctored by one of the two leading authors of this study, both of whom identified as White, one identified as female, one as male, and one was faculty at the same institution as students in the current study.

Students were asked a series of 11 semi-structured questions along with potential follow-up questions and probes focused specifically on their Calculus II or Physics courses (see Supplemental Materials for all interview prompts). For example, interviewers asked participants to share how they were personally coping with the changes due to COVID-19 and the virtual transition, how their Calculus II or Physics course was going during the transition, how this transition affected their academic performance, motivation, classroom community, and feelings of "belongingness." All participants responded to each question. Interviews had an average duration of $45.8 \mathrm{~min}(\mathrm{SD}=13.8 \mathrm{~min})$, not including survey completion time.

\section{Results}

\subsection{Quantitative Analysis}

To explore the impacts of the faculty instruction mode during the virtual online transition prompted by the COVID-19 pandemic, we computed descriptive statistics, examined intercorrelations between variables, and ran ordinary least squares (OLS) multiple regression models. Concerning the latter, we ran regressions with belonging and engagement indicators as main outcomes, the instruction mode as the predictor, and race/ethnicity as a moderating variable. Financial and health impacts of COVID-19 were included as a covariate to adjust for threats to students' basic needs. All variables were standardized around the mean to ease interpretation. Quantitative analyses were conducted using $R$ version 4.0.3.

We also tested for interactions between teaching practices and gender. No significant interactions were found for all outcomes and including interaction terms did not substantially change the significance or sign of any results. Results of the gender interactions are presented in Table S1 of the Supplemental Materials.

\subsection{Quantitative Findings}

The predictor and response variables were examined for skewness and kurtosis. Skewness ranged between -0.59 and 1.52 and kurtosis ranged between -1.68 and 2.47, which were both acceptable [57]. We also inspected graphs of residual variances and 
conducted Breusch-Pagan tests for each model to confirm that the data did not violate homoskedasticity assumptions (all $p>0.172$ ). Descriptive statistics are presented in Table 1 .

Notably, descriptive statistics showed that students reported that their instructors most frequently required individual work from students (median $=$ " $80-100 \%$ of the time"), interactive live lectures (median = "40-60\% of the time"), noninteractive live lectures $($ median $=$ "40-60\% of the time"), prerecorded lectures, $($ median $=$ " $20-40 \%$ of the time"), breakout groups (median = "20-40\% of the time"), and least frequently engaged in synchronous discussion (median $=$ "0-20\% of the time").

Teaching Methods That Explain Belonging and Engagement (RQ1), Particularly for Racially Under-Represented Students (RQ2)

Our first and second research questions were: "To what extent are student-reported online teaching methods related to their sense of belonging and affective/cognitive engagement in STEM during times of crises? Are the impacts of these teaching methods different for ethnically/racially under-represented students?" To address these questions, we ran three OLS regression models for each of the four response variables (belonging, emotions, cognitive engagement, and STEM interest). The first model included only students' reports of their instructors' teaching methods as explanatory variables, the second model included the same predictors as well as the COVID-19 threat and impacts scale, and the third model also included interactions between race/ethnicity and teaching methods. Namely, an indicator variable was created to represent Black or African American or Hispanic or Latino students (making up $42 \%$ of the sample, hereafter referred to as "Black/Hispanic"). Full results of race/ethnicity interactions, including all standardized coefficients, are presented in Table 2.

Table 2. Standardized OLS regression coefficients for instructional practices predicting psychological and cognitive well-being outcomes.

\begin{tabular}{|c|c|c|c|c|c|c|c|c|c|}
\hline \multirow{2}{*}{$\begin{array}{l}\text { Predictor } \\
\text { Prerecorded Lecture }\end{array}$} & \multicolumn{3}{|c|}{$\begin{array}{c}\text { Belonging } \\
\beta \\
(\mathrm{SE})\end{array}$} & \multicolumn{3}{|c|}{$\begin{array}{c}\text { Positive Emotions } \\
\beta \\
\text { (SE) }\end{array}$} & \multicolumn{3}{|c|}{$\begin{array}{c}\text { Negative Emotions } \\
\beta \\
\text { (SE) }\end{array}$} \\
\hline & $\begin{array}{c}0.108 \\
(0.189)\end{array}$ & $\begin{array}{c}0.159 \\
(0.188)\end{array}$ & $\begin{array}{c}0.198 \\
(0.228)\end{array}$ & $\begin{array}{l}-0.126 \\
(0.189)\end{array}$ & $\begin{array}{c}-0.1 \\
(0.192)\end{array}$ & $\begin{array}{c}0.011 \\
(0.293)\end{array}$ & $\begin{array}{l}0.270 \sim \\
(0.155)\end{array}$ & $\begin{array}{c}0.206 \\
(0.159)\end{array}$ & $\begin{array}{c}0.094 \\
(0.242)\end{array}$ \\
\hline Noninteractive Live Lecture & $\begin{array}{c}-0.339 \sim \\
(0.192)\end{array}$ & $\begin{array}{c}-0.454 \\
(0.204)\end{array}$ & $\begin{array}{c}-0.554 \text { * } \\
(0.248)\end{array}$ & $\begin{array}{c}-0.066 \\
(0.156)\end{array}$ & $\begin{array}{r}-0.129 \\
(0.174)\end{array}$ & $\begin{array}{c}0.057 \\
(0.264)\end{array}$ & $\begin{array}{l}-0.051 \\
(0.155)\end{array}$ & $\begin{array}{c}0.110 \\
(0.162)\end{array}$ & $\begin{array}{c}0.087 \\
(0.250)\end{array}$ \\
\hline Interactive Live Lecture & $\begin{array}{l}-0.122 \\
(0.253)\end{array}$ & $\begin{array}{l}-0.093 \\
(0.248)\end{array}$ & $\begin{array}{l}-0.452 \\
(0.276)\end{array}$ & $\begin{array}{c}0.144 \\
(0.192)\end{array}$ & $\begin{array}{c}0.140 \\
(0.193)\end{array}$ & $\begin{array}{c}0.102 \\
(0.291)\end{array}$ & $\begin{array}{c}0.087 \\
(0.190)\end{array}$ & $\begin{array}{c}0.095 \\
(0.180)\end{array}$ & $\begin{array}{l}-0.001 \\
(0.275)\end{array}$ \\
\hline Discussion & $\begin{array}{l}-0.201 \\
(0.190)\end{array}$ & $\begin{array}{l}-0.095 \\
(0.199)\end{array}$ & $\begin{array}{c}-0.208 \\
(0.274)\end{array}$ & $\begin{array}{l}-0.085 \\
(0.181)\end{array}$ & $\begin{array}{l}-0.056 \\
(0.185)\end{array}$ & $\begin{array}{l}-0.259 \\
(0.310)\end{array}$ & $\begin{array}{c}0.021 \\
(0.179)\end{array}$ & $\begin{array}{l}-0.053 \\
(0.172)\end{array}$ & $\begin{array}{l}-0.278 \\
(0.293)\end{array}$ \\
\hline Breakout groups & $\begin{array}{c}0.216 \\
(0.186)\end{array}$ & $\begin{array}{c}0.0360 \sim \\
(0.207)\end{array}$ & $\begin{array}{l}0.712^{*} \\
(0.251)\end{array}$ & $\begin{array}{l}0.440^{*} \\
(0.171)\end{array}$ & $\begin{array}{l}0.513^{*} \\
(0.192)\end{array}$ & $\begin{array}{l}0.524 \sim \\
(0.259)\end{array}$ & $\begin{array}{l}-0.074 \\
(0.173)\end{array}$ & $\begin{array}{l}-0.259 \\
(0.182)\end{array}$ & $\begin{array}{l}-0.083 \\
(0.245)\end{array}$ \\
\hline Individual work & $\begin{array}{c}-0.247 \\
(0.230)\end{array}$ & $\begin{array}{l}-0.095 \\
(0.248)\end{array}$ & $\begin{array}{l}-0.019 \\
(0.292)\end{array}$ & $\begin{array}{c}0.166 \\
(0.174)\end{array}$ & $\begin{array}{c}0.221 \\
(0.186)\end{array}$ & $\begin{array}{c}0.141 \\
(0.281)\end{array}$ & $\begin{array}{l}0.361^{*} \\
(0.176)\end{array}$ & $\begin{array}{c}0.221 \\
(0.177)\end{array}$ & $\begin{array}{c}0.148 \\
(0.266)\end{array}$ \\
\hline COVID-19 Threat & & $\begin{array}{c}(0.248) \\
-0.379 \\
(0.258)\end{array}$ & $\begin{array}{c}(0.292) \\
-0.617 \\
(0.251)\end{array}$ & & $\begin{array}{l}(0.186) \\
-0.166 \\
(0.196)\end{array}$ & $\begin{array}{l}(0.281) \\
-0.124 \\
(0.214)\end{array}$ & & $\begin{array}{l}0.420 \text { * } \\
(0.183)\end{array}$ & $\begin{array}{l}(0.266) \\
0.426^{*} \\
(0.203)\end{array}$ \\
\hline Black/Hispanic & & & $\begin{array}{l}-0.210 \\
(0.375)\end{array}$ & & & $\begin{array}{l}-0.404 \\
(0.346)\end{array}$ & & & $\begin{array}{c}0.090 \\
(0.334)\end{array}$ \\
\hline Prerecorded Lecture * & & & 0.599 & & & -0.286 & & & 0.376 \\
\hline Black/Hispanic & & & $(0.416)$ & & & $(0.346)$ & & & $(0.335)$ \\
\hline Noninteractive Lecture * & & & 0.424 & & & -0.398 & & & 0.042 \\
\hline Black/Hispanic & & & $(0.387)$ & & & $(0.348)$ & & & $(0.332)$ \\
\hline Interactive Lecture * & & & $1.578 * *$ & & & 0.179 & & & 0.089 \\
\hline Black/Hispanic & & & $(0.520)$ & & & $(0.434)$ & & & $(0.411)$ \\
\hline Discussion * Black/Hispanic & & & $\begin{array}{c}0.356 \\
(0.399)\end{array}$ & & & $\begin{array}{c}0.387 \\
(0.423)\end{array}$ & & & $\begin{array}{c}0.443 \\
(0.400)\end{array}$ \\
\hline Breakout groups * & & & -0.561 & & & 0.003 & & & -0.437 \\
\hline Black/Hispanic & & & $(0.401)$ & & & $(0.418)$ & & & $(0.429)$ \\
\hline Individual work * & & & 0.446 & & & 0.414 & & & 0.020 \\
\hline Black/Hispanic & & & $(0.475)$ & & & $(0.407)$ & & & $(0.393)$ \\
\hline Observations & 34 & 34 & 34 & 43 & 43 & 43 & 42 & 42 & 42 \\
\hline $\mathrm{R}^{2}$ & 0.209 & 0.27 & 0.571 & 0.204 & 0.22 & 0.337 & 0.223 & 0.328 & 0.413 \\
\hline Adjusted $\mathrm{R}^{2}$ & 0.033 & 0.073 & 0.255 & 0.071 & 0.064 & 0.005 & 0.090 & 0.189 & 0.109 \\
\hline
\end{tabular}


Table 2. Cont.

\begin{tabular}{|c|c|c|c|c|c|c|c|c|c|}
\hline \multirow{2}{*}{$\begin{array}{l}\text { Predictor } \\
\text { Prerecorded Lecture }\end{array}$} & \multicolumn{3}{|c|}{$\begin{array}{c}\text { STEM Interest } \\
\beta \\
(\mathrm{SE})\end{array}$} & \multicolumn{3}{|c|}{$\begin{array}{c}\text { Cognitive Engagement } \\
\beta \\
\text { (SE) }\end{array}$} & \multicolumn{3}{|c|}{$\begin{array}{c}\text { Perceptions of Teaching } \\
\text { Quality } \\
\beta \\
\text { (SE) }\end{array}$} \\
\hline & $\begin{array}{l}-0.197 \\
(0.158)\end{array}$ & $\begin{array}{l}-0.128 \\
(0.152)\end{array}$ & $\begin{array}{c}-0.038 \\
(0.219)\end{array}$ & $\begin{array}{c}0.06 \\
(0.164)\end{array}$ & $\begin{array}{c}0.127 \\
(0.149)\end{array}$ & $\begin{array}{c}0.239 \\
(0.229)\end{array}$ & $\begin{array}{c}0.055 \\
(0.155)\end{array}$ & $\begin{array}{c}0.076 \\
(0.149)\end{array}$ & $\begin{array}{l}-0.089 \\
(0.229)\end{array}$ \\
\hline Noninteractive Live Lecture & -0.487 ** & $-0.684^{* *}$ & -0.502 * & $\begin{array}{c}-0.084 \\
(0.158)\end{array}$ & $\begin{array}{r}-0.249 \\
(0.166)\end{array}$ & $\begin{array}{l}-0.016 \\
(0.239)\end{array}$ & $\begin{array}{c}0.043 \\
(0.145)\end{array}$ & $\begin{array}{r}-0.009 \\
(0.162)\end{array}$ & $\begin{array}{l}-0.072 \\
(0.251)\end{array}$ \\
\hline Interactive Live Lecture & $\begin{array}{l}-0.092 \\
(0.179)\end{array}$ & $\begin{array}{l}-0.104 \\
(0.164)\end{array}$ & $\begin{array}{l}-0.004 \\
(0.244)\end{array}$ & $\begin{array}{c}0.106 \\
(0.195)\end{array}$ & $\begin{array}{c}0.097 \\
(0.184)\end{array}$ & $\begin{array}{c}0.333 \\
(0.264)\end{array}$ & $\begin{array}{l}0.397^{*} \\
(0.179)\end{array}$ & $\begin{array}{l}0.395^{*} \\
(0.180)\end{array}$ & $\begin{array}{c}0.054 \\
(0.277)\end{array}$ \\
\hline Discussion & $\begin{array}{c}0.178 \\
(0.170)\end{array}$ & $\begin{array}{l}0.279 \sim \\
(0.160)\end{array}$ & $\begin{array}{c}0.100 \\
(0.260)\end{array}$ & $\begin{array}{c}0.167 \\
(0.183)\end{array}$ & $\begin{array}{c}0.242 \\
(0.176)\end{array}$ & $\begin{array}{l}-0.053 \\
(0.281)\end{array}$ & $\begin{array}{c}0.030 \\
(0.168)\end{array}$ & $\begin{array}{c}0.054 \\
(0.172)\end{array}$ & $\begin{array}{c}0.197 \\
(0.294)\end{array}$ \\
\hline Breakout groups & $\begin{array}{l}-0.075 \\
(0.162)\end{array}$ & $\begin{array}{c}0.112 \\
(0.163)\end{array}$ & $\begin{array}{c}0.329 \\
(0.219)\end{array}$ & $\begin{array}{c}0.216 \\
(0.173)\end{array}$ & $\begin{array}{l}0.403 * \\
(0.183)\end{array}$ & $\begin{array}{l}0.438 \sim \\
(0.235)\end{array}$ & $\begin{array}{c}0.164 \\
(0.159)\end{array}$ & $\begin{array}{c}0.223 \\
(0.179)\end{array}$ & $\begin{array}{c}0.187 \\
(0.246)\end{array}$ \\
\hline Individual work & $\begin{array}{c}0.235 \\
(0.165)\end{array}$ & $\begin{array}{l}0.371^{*} \\
(0.159)\end{array}$ & $\begin{array}{l}0.589^{*} \\
(0.236)\end{array}$ & $\begin{array}{l}0.314 \sim \\
(0.176)\end{array}$ & $\begin{array}{l}0.455^{*} \\
(0.178)\end{array}$ & $\begin{array}{l}0.517 \sim \\
(0.254)\end{array}$ & $\begin{array}{l}-0.133 \\
(0.162)\end{array}$ & $\begin{array}{c}-0.088 \\
(0.173)\end{array}$ & $\begin{array}{l}-0.253 \\
(0.267)\end{array}$ \\
\hline COVID-19 Threat & & $\begin{array}{c}-0.476 \text { ** } \\
(0.172)\end{array}$ & $\begin{array}{c}-0.584^{* *} \\
(0.191)\end{array}$ & & $\begin{array}{c}-0.429 * \\
(0.187)\end{array}$ & $\begin{array}{l}-0.291 \\
(0.194)\end{array}$ & & $\begin{array}{c}-0.135 \\
(0.183)\end{array}$ & $\begin{array}{l}-0.211 \\
(0.203)\end{array}$ \\
\hline $\begin{array}{l}\text { Black/African American or } \\
\text { Hispanic }\end{array}$ & & & $\begin{array}{c}0.377 \\
(0.304)\end{array}$ & & & $\begin{array}{l}-0.659 * \\
(0.314)\end{array}$ & & & $\begin{array}{c}0.168 \\
(0.329)\end{array}$ \\
\hline Prerecorded Lecture * & & & 0.051 & & & -0.213 & & & 0.276 \\
\hline Black/Hispanic & & & $(0.290)$ & & & $(0.314)$ & & & $(0.329)$ \\
\hline Noninteractive Lecture * & & & -0.331 & & & -0.353 & & & -0.035 \\
\hline Black/Hispanic & & & $(0.293)$ & & & $(0.316)$ & & & $(0.331)$ \\
\hline Interactive Lecture * & & & -0.008 & & & -0.391 & & & 0.644 \\
\hline Black/Hispanic & & & $(0.367)$ & & & $(0.394)$ & & & $(0.413)$ \\
\hline Discussion * Black/Hispanic & & & $\begin{array}{c}0.114 \\
(0.354)\end{array}$ & & & $\begin{array}{c}0.619 \\
(0.383)\end{array}$ & & & $\begin{array}{l}-0.242 \\
(0.402)\end{array}$ \\
\hline Breakout groups * & & & -0.487 & & & -0.264 & & & 0.167 \\
\hline Black/Hispanic & & & $(0.358)$ & & & $(0.379)$ & & & $(0.397)$ \\
\hline Individual work * & & & -0.368 & & & 0.148 & & & 0.263 \\
\hline Black/Hispanic & & & $(0.351)$ & & & $(0.369)$ & & & $(0.387)$ \\
\hline Observations & 42 & 42 & 42 & 43 & 43 & 43 & 43 & 43 & 43 \\
\hline $\mathrm{R}^{2}$ & 0.313 & 0.44 & 0.54 & 0.183 & 0.29 & 0.455 & 0.311 & 0.322 & 0.401 \\
\hline Adjusted $\mathrm{R}^{2}$ & 0.196 & 0.325 & 0.301 & 0.047 & 0.148 & 0.182 & 0.197 & 0.186 & 0.101 \\
\hline
\end{tabular}

Note. Boldfaced values indicate statistically significant results for predictors. $\sim p<0.1 ;{ }^{*} p<0.05 ;{ }^{* *} p<0.01$.

Belonging. After adjusting for the COVID-19 threat, belonging was negatively predicted by exposure to non-interactive synchronous lectures $(p=0.035)$, and was marginally positively predicted by engaging in breakout groups $(p=0.094)$. We found similar results after including the Black/Hispanic indicator and interaction terms for noninteractive lectures $(p=0.038)$ and breakout groups $(p=0.011)$, as well as a significant and positive interaction effect of Black/Hispanic students who reported higher belonging with interactive lectures $(p=0.007)$ and negative effects of the COVID-19 threat $(p=0.024)$.

Emotions. When positive emotions were the main outcome, we found that the reported use of breakout groups was a positive predictor before and after adjusting for COVID-19 threats and interactions (with $p$ s ranging from 0.014 to 0.053). Higher negative emotions were related to individual work $(p=0.049)$ and marginally associated with prerecorded lectures $(p=0.090)$. After including the COVID-19 threat, however, teaching methods were no longer significant predictors of negative emotions. We found no significant interactions with race/ethnicity.

STEM Interest. Non-interactive lectures predicted a lower reported interest in STEM for all three models ( $p$ s ranging from less than 0.001 to 0.032). When the COVID-19 threat was included as a covariate, individual work was positively associated with higher STEM interest $(p=0.026)$, and the COVID-19 threat was negatively associated with STEM interest $(p=0.009)$. The significance of these associations was maintained after interaction terms were included. No significant interactions emerged with teaching practices and race/ethnicity.

Cognitive Engagement. Cognitive engagement was positively predicted by individual work for all three models ( $p$ s from 0.015 to 0.083 ). The reported use of breakout groups was significant only after adjusting for COVID-19 threats $(p=0.035)$. Black/Hispanic students were associated with a lower cognitive engagement than white students $(p=0.045)$. 
Student Perceptions of Teaching Quality. Students' perceptions of teaching quality were significantly predicted by the use of interactive live lectures, before $(p=0.033)$ and after adjusting for COVID-19 threats $(p=0.035)$, but not after including race interaction terms $(p=0.848)$.

\subsection{Qualitative Analysis}

All interviews were recorded through Zoom, transcribed, and open coded by the lead author. Through open coding, several themes emerged related to student perceptions of instruction that students received, as well as the sources, dimensions, and impacts of student feelings of inclusion, belonging, and interpersonal connection. Codes were created, compared, consolidated, and used to create a codebook, which was revised by another author before it was used by two undergraduate research assistants who independently coded all transcripts using NVivo 12. Over the course of eight weekly meetings, the coders met with the lead author and other research team members on occasion as they progressed through coding to discuss, interpret, consolidate, and occasionally revise the definition of codes as part of the calibration process [58]. When coders had completed coding all transcripts independently (other than the exemplar interviews, which were partially coded together), an NVivo query was used to compute an inter-rater agreement, which revealed that all central codes had an agreement greater than $95 \%$ at the sentence level. Incidents of codes were included in analyses if they were coded by one or more of the coders. The final codebook with definitions is presented in the Supplementary Materials. To improve trustworthiness, we also reported negative cases that differed from the typical trends found in the data $[59,60]$.

\subsection{Qualitative Findings}

Findings provided insights into how students' interactions with faculty and peers affected their engagement and feelings of belonging in STEM. Interviews highlighted both positive and negative interactions with students and faculty and delineated various teaching approaches that facilitated or hindered belonging. In this section, we present a summary of student perceptions, followed by a case study to illustrate the codes and dimensions uncovered in the interviews.

\subsubsection{Online Interactions That Support or Hinder Belonging and Engagement (RQ3)}

Students shared their experiences of interactions that supported their feelings of belonging and affective engagement. Interactions that supported belonging stemmed primarily from interactions with peers, faculty, and derived from their own sense of confidence. In what follows, we presented examples of these sources of student belonging and engagement. A summary of the codes and frequencies of students' reported sources of belonging and engagement are shown in Table 3.

Table 3. Students' reported sources of belonging and affective engagement during interviews ( $N=21)$.

\begin{tabular}{lcc}
\hline Sources of Belonging & Number of Students & $\%$ \\
\hline Positive peer-peer interaction (in class) & 10 & $46 \%$ \\
Positive peer-peer interaction (outside of class) & 8 & $38 \%$ \\
Campus communities & 17 & $8 \%$ \\
Faculty caring & 13 & $62 \%$ \\
Competency belonging & 8 & $38 \%$ \\
\hline
\end{tabular}

A key theme that emerged from the data was the presence of two different types of belonging in students' calculus and physics courses during the virtual transition. Social belonging was linked to social interactions and friendships with students and faculty in synchronous instructional settings. Competency belonging emerged as a separate source of belonging where students felt as if they belonged in the course based on the level of 
competency they had consistently demonstrated in their current and prior STEM courses. We detailed these findings below.

Student-student interactions. A majority (61\%) of students reported during interviews that they felt a sense of social connection with their peers, reporting the presence of positive interpersonal relationships, feelings of acceptance, inclusion, or belonging as stemming from their interactions with peers in STEM. One student's remark underscored many students' perceptions of the centrality of synchronous classrooms in initiating connections with peers:

I would say that going to lecture is what really, is what keeps me connected to the classroom community, but also I had friends in the class, so we keep in contact through social media. [We] just text each other. "Oh, when's this due?" for example, or "Oh, you're going to lecture, right?", "Oh, did you understand this? I'm a little bit confused. You get that?" You know, [we] just text each other and ask questions. But it's really helpful going to lecture because there's like students watching so they can enter questions into the chat.

In contrast, students in asynchronous courses often shared challenges of connecting with their peers. A student in an asynchronous physics course stated that connecting with peers was near impossible, "Honestly, sometimes I forget there's other people in the class." Another in the same class elaborated:

...now you don't have any physical interaction, I really don't feel included as a part of a class. I'm just looking at a screen the whole time. I don't know how you can really feel any inclusion there unless there was like a chat forum or something like that.

This illustrates that, in most cases, students expressed feelings of motivation and positive affect associated with peer-to-peer interactions facilitated by live, synchronous interactions and negative affect in the absence of social interaction. However, in seeking negative cases that did not fit the general trend $[59,60]$, we found that some students were able to maintain connections with students despite the isolation imposed by their asynchronous courses. A student in an asynchronous physics course commented on the importance of her engineering friends during the transition for "exchanging information," noting that "We still remind each other to do homework, to study for the test, and stuff. We are all engineering and computer science girls. So that always motivates me." We also found that students in synchronous courses sometimes found it difficult to make new friends, "But in terms of like talking to new people in the classroom and like asking them for help. Like, I haven't really done that. I feel like that's more difficult because it's kind of like, where do I start? Like it's kind of awkward in that sense."

Students also shared feelings of social belonging in STEM resulting from peer relations that were not connected to the classroom. Some ( $8 \%$ ) derived a sense of peer connection through campus communities outside of their STEM courses (e.g., clubs, sororities, etc.). For example, a student noted that they felt a sense of membership as a result of being in a campus club, "We're talking to each other almost every night on Discord or just playing video games together if we have time." We found no evidence that this form of connection was supported through instruction.

Student-faculty interactions. The majority of students (62\%) derived a sense of social connection and belonging from interactions with their professors. This was expressed in terms of positive relationships and feelings of acceptance and inclusion from the professor. Some underlined the importance of feeling cared for by faculty:

I know [the instructor] cares about every single one of us. She even mentions it ... it's almost like a second family in the sense that she does the little, little things to make you feel like you are included, such as, you know, addressing her by her first name rather than the professor or, you know, just asking how our day is, sharing our own day. So definitely you usually don't feel like you're excluded or isolated away from that. 
Others expressed a positive affect and motivation linked to feelings of personal identification and relatability with their professor. A student in an asynchronous course stated, "And she's a, she's a very good professor in the fact that she always like cheers us up like, she always motivates us to keep working. And she herself is very hardworking as well so, yeah." Conversely, some students lamented that their professors teaching asynchronously had become less available for support during the onset of the pandemic:

I thought [the instructor] would have done videos and then posted them online, but she's kind of distanced herself from the class...Which is a shame because I like her as a person, like I think she's so sweet, but I just, I don't like how the class is now. Because she's not really teaching it.

These contrasting statements illustrate the importance that students placed on feeling close with faculty during this time of crisis and feeling their presence in videos, even in an asynchronous mode. Warm affect and motivation seemed to stem from students' feelings of connection and relatability with faculty, whereas students who lost contact with their instructors expressed less hope and more apathy. Clearly, social connections with faculty were also important after the virtual transition.

Competency belonging. Some students, regardless of the challenges they faced in their courses, experienced what we term competency belonging, which is feeling a sense of inclusion in a course, major, or field by drawing on their positive past performance in STEM courses and their demonstrated high levels of competency in the subject matter. As such, they feel they belong in the course because they are competent in the subject matter. For example, after expressing feelings of disconnection from peers in her class, one student noted, "I feel like I'm still, I still belong in the class... in the sense that I know, I like I have the background knowledge of, I know enough math to be in calculus." This type of belonging appeared to be less about belonging on a social level with other faculty and students but rather belonging to the STEM course due to their ability and performance.

Other students shared feeling low-competency belonging, expressing that they felt as if they do not belong because of negative prior experiences in their STEM courses that signaled little STEM ability or competency:

In grade school, I was never really good at math. I had a professor. I went to a professor's office hours for help. And I was like, hey I'm confused on this question. And he said after kind of like a conversation we had about this question. He ended up telling me, oh, you have the liberal arts brain. I have the math brain. Maybe this isn't for you ... I still struggle with that feeling of belongingness because I don't have the STEM background.

Overall, this suggested that students' sense of competency served as a source of belonging in the course. It is important to note that this type of belonging appears to be qualitatively different than the construct of relatedness (belonging) as outlined in the Self-Determination Theory. Relatedness in the Self-Determination Theory refers to a "connectedness with others" [21]. Our data suggest that competency belonging is an alternate type of belonging that emerges from performance in a course or field rather than interpersonal relationships. Competency belonging rests on students' judgment of their abilities to excel in the subject matter of the course, whereas relatedness is based on students' perceptions of the quality of their social relationships, connections, and may implicate their social identities. This novel concept-belonging competency-warrants further investigation in future research.

\subsubsection{Summary}

The interviews suggested that students meet their belonging needs both inside and outside the classroom through social interaction and connecting with both peers and faculty. Students reported that genuine faculty caring facilitated a sense of social belonging. Students with greater feelings of competency and subject matter knowledge described feeling a higher sense of competency belonging in the course, even if they did not feel a sense of connectedness with peers or the faculty member (social belonging). 


\subsection{Embedded Case Studies}

To further explore how students' experiences either supported or hindered their belonging and engagement in rich detail [47], we synthesized the data and illustrated the themes, codes, and quantitative findings presented in the sections above in two embedded case studies [59-62] presented in the form of short vignettes. The cases we considered were bounded by the classroom [62], and each classroom consisted of multiple units of analysis—student experiences (secondary unit) within classrooms (primary unit) [61].

In the vignettes that follow, we highlighted four students' experiences in two virtual classrooms led by two different instructors (two students per classroom). We compared two cases to highlight classrooms that varied in how their approaches to the virtual transition (synchronous vs. asynchronous teaching methods) were perceived by students. We told the story of two physics classrooms (rather than one physics and one mathematics class) to ease comparison between cases and we also showcased two students within each of these classrooms to illustrate the range of experiences within each setting. All names were pseudonyms, and the gender of faculty members were disguised to protect their identity and pronouns changed to "They/Them/Their."

\subsubsection{A Synchronous Physics Course}

The first physics course we present was taught by an adjunct professor who, as evidenced by student interviews, represented the case of an instructor who cared about the students, showed a substantial grading flexibility and adaptability, and responded swiftly to crises with action. Prior to the pandemic, this course was delivered face-toface, but after transitioning to online learning, the instructor adopted a synchronous platform. The instructor conducted the online course synchronously multiple times per week, structured each session around a lecture, provided live demonstrations of physics concepts, and encouraged students to make frequent use of the chat function in the livestream. This classroom represented the case of a synchronous course, where students had multiple outlets to connect with peers and the instructor, and the faculty seemed to exhibit pedagogical decisions and technological skills that nurtured students' feelings of inclusion and engagement, which we provided evidence for in the following cases.

Ananya. The first student from the synchronous course we present was Ananya, a first-year student majoring in Civil Engineering. Ananya identified her race/ethnicity as "Asian (e.g., Japanese, Chinese, Vietnamese)" and gender as "female." She participated in a one-on-one interview from her private bedroom in her family's home. She is the case of a student who responded well to synchronous instruction, with the added support of a pre-existing friendship network.

When asked how her life had changed as a result of the pandemic, Ananya stated that the transition was difficult, "I actually enjoyed going to class every day and getting to collaborate with my friends ... But now that I'm online, it's just simply not the same experience," adding that "it's really hard to focus." She reported keeping busy by doubling down on schoolwork and learning how to play the guitar through YouTube videos to cope with the changes. She noted that the physics course had been a positive experience for her, despite having to transition to YouTube because of Zoombombing. "[The instructor is] actually making a really big effort to actually teach us everything and make sure that we walk out of physics with like a good understanding of what's happening."

When asked about the classroom community and if/how she stays connected with her peers and professors, Ananya responded by emphasizing the importance she placed on attending the synchronous lecture: "I would say that going to lecture is what really, is what keeps me connected to the classroom community ... ". She later elaborated that, "[The instructor's] face being there kind of helps" and that engaging with the professor and other students using the chat function during Q\&A was particularly helpful for her understanding.

She also expressed that she stayed connected through her friendship circle, "... also I had friends in the class, so we keep in contact through social media." She added that she 
and her friends managed to keep each other on track academically though text message to check in on due dates and lecture announcements. When asked if she felt as if she belonged in physics, she responded "I would say I do feel like I belong in physics ... I think it's a really positive environment. No one's judging you for like asking questions or anything like that. Yeah."

Benita. The second student that we present from this synchronous course was Benita, a biochemistry major. On the survey, she identified as "female" and "Hispanic, Latinx, or Spanish origin" and participated in this interview along with another student. Benita was displaced as a result of the pandemic, seemed to have less of a pre-existing support network of peers to rely on for help, but remained optimistic with the support from feeling connected to her class through synchronous chat, email, and office hours.

She began the interview by noting that she was "just crashing at [her] friends' place," not wanting to risk infecting her grandparents by moving home. She also noted that she had, "very limited resources. So, it's really hard for me to go anywhere, to go get groceries, to just do anything in general." Similar to Benita, many students interviewed had to make significant changes to their living situation and were under financial strains, some losing their jobs due to closures.

When asked how class had been going in Physics, Benita began by noting the positive changes to instruction. She stated that the instructor sometimes "talks really fast and it's hard for me to take down notes," but appreciated that virtual lectures allowed her to slow things down and review lectures. She also stated, "I don't have to be afraid of asking questions because no one's going to see me. No one's going to look at me. So, it's definitely helped me in a more positive direction." Similar to Benita, many female students in challenging STEM majors noted that they appreciated that the virtual transition brought more anonymous participation by using chat features on synchronous platforms. In particular, two additional female students of color mentioned feeling more comfortable to ask questions in class as their questions would not be associated with their physical characteristics. Benita later elaborated on her appreciation of synchronous chat when asked if she had maintained a sense of belonging in class,

I mean, I was never a physics person, and I can't say that I feel like I belong in the first place, but... I feel like I'm able to learn better now, and that the people in the chat, its people are very positive and very happy. And it just makes like the whole class feel like it's normal and everything feels fine when you're in that class.

Benita noted that she did not stay socially connected with her peers. She stated, "I don't know a lot of people in physics. But ... one of my roommates I'm living with, he has taken physics before, so I just ask him for help..." Her main source of connection to the physics class was through her professor, who she contacted through email and synchronous office hours, "It's easy to talk to [the instructor] as long as you reach out [through email] and [the instructor] also holds office hours."

Benita highlighted the common situation of a student who faced challenges due to the pandemic, was not particularly well-connected with students in the classroom, but was able to feel social belonging through her connection with the professor and using the chat feature during a synchronous lecture. Benita highlighted the importance of creating and protecting comfortable spaces for students to stay in contact with each other, the instructor, and to learn. Further, her case highlighted the general resilience and adaptability of students and the positive impacts of faculty's responsiveness during a time of crisis.

\subsubsection{An Asynchronous Physics Course}

The second physics course we present was also taught by an adjunct professor. Prior to the pandemic, the course was delivered in a physical classroom and was received positively from students. Due to the transition to online learning, this course adopted an asynchronous physics platform, wherein students completed a series of online modules that included videos, slideshows, animations, and built-in homework and assessments 
presented in a specific order, for which students received both formative and summative feedback. The curriculum materials were premade, but allowed the instructor to make modifications. The instructor held regular office hours for their very large classes ( 120 students) and, to our knowledge, this course did not include an online discussion forum for student interaction.

This classroom represented the case of an asynchronous course where students had relatively few outlets to connect with peers or the instructor, and the faculty exhibited less flexibility to changing circumstances. Students in this course generally expressed negative affective experiences as a result, while a rare few were able to adapt, self-teach, and draw from their competency belonging and prior experiences and personal identity to persist in the challenging environment.

Chris. The first student that we present from this asynchronous course was Chris, a second year Mechanical Engineering major that identified as "White" and "male." He represented the case of a student who, despite having physical and social resources of his own, felt unsupported by his Physics professor after the transition to online learning due to a loss of interpersonal contact.

When asked how his life had changed as a result of the pandemic, Chris noted that, while he took the pandemic seriously, he did not endure any major changes to his living or financial situation. He shared that "it was not like a super hard change for me in particular." He continued to do schoolwork from home and maintained connections with his peers in class through text messages.

However, when asked about how physics was going, Chris expressed that the transition to asynchronous learning was a negative one due to decreased opportunities for interpersonal contact with the professor. He thought that, in general, demanding STEM courses required "a bit more social interaction with your professor" to ask questions and receive help, but that, in this asynchronous course "that doesn't happen." He stated, "I remember, the first time I tried to go to office hours. I probably waited like an hour or two and then, basically the thing ended because [the professor] was outside office hours at that point... that was difficult." Chris seemed to highly value contact with the professor and having the space to ask questions in real time.

When asked about classroom community and if/how connections were maintained in physics, he communicated a sense of loss in interpersonal communication, commenting that office hours were a particularly difficult loss for him,

... talking with someone, you know, outside of class or after class or in class, talking with your professors during the office hours. A lot of stuff just flat out doesn't happen now honestly ... But as far as me trying to adapt and change and try and continue those relationships, it's really hard because the office hour thing, you know, I can't really chit chat with my professors in a lighthearted manner because the fact that they usually have one office hour time available for all of our students.

Chris seemed to highly value informal contact with his peers and professor, later saying that he missed having "... the lightheartedness of the conversation," "body language," and "the comfort of having another person there in your learning experience that it might help to ease whatever stress you're having." Chris expressed that human contact with his professors gave the challenging, abstract physics content a human quality, ultimately reducing his levels of stress. While comparing physics class to his prior experiences in calculus classes, he noted that, "after like going into their office hours and being able to talk to them, it kind of eases you up a little bit."

Additionally, Chris seemed to perceive a general sense of inflexibility from the instructor with regard to assignments. He noted that, "The formats of the tests didn't change at all ... [the professor] gave us like $10 \mathrm{~min}$ to submit like the document or whatever, the Blackboard or scan it and do all that stuff." The pressures of submitting virtual assignments that had strict time limits was a common source of stress for many students that we interviewed in this course. 
Similar to many students in this asynchronous class, Chris expressed feelings of being unsupported by the professor, stemming from the inflexibility and impersonal nature of the online modules. Similar to Chris, many students highly valued interpersonal experiences with their peers and the professor and shared a sense of profound loss in the changed circumstances. Yet, despite generally negative sentiment, a few students were able to experience a sense of course belonging by relying on their existing social network.

Denise. Denise was another student in the asynchronous physics course. She was an international student learning English as a second language who identified as Asian and as a woman majoring in Mechanical Engineering. When asked how things were going in physics, she expressed a general air of positivity and self-sufficiency:

I'm doing pretty well, actually, because like, I've been, like, I'm pretty good at self-study... I always read the materials like before classes so that I will be able to understand more, so I actually do things on my own. So ever since we went online, it was not hard for me because I got used to doing everything on my own.

When asked about the transition in physics in particular, she explained her initial shock at the drastic change from live lectures to online modules, "we were all scared ... we just watched [video lectures] and then answer some questions ... we have all gotten used to [the professor] talking about the materials because the way [the professor] explains the concepts is very understandable." The contrast between pre- and post-pandemic was palpable among students in the instructor's class. Denise sympathized with her peers' feelings of inflexibility, noting that the class was only given fifteen minutes to complete quizzes and that, "many students cannot finish it on time and then we have to also upload it on [the course website]. So, we all think that the time limit is not enough for us to finish."

However, despite these challenges, she stated that she eventually "got used to it," explaining that the videos, homework, and quizzes seemed straightforward. Her confidence in her abilities and her academic performance stood out as a salient source of feeling connected and belonging in the physics class. That is, she demonstrated the case of relying on her competency belonging as a way to motivate herself to persevere in the course. Denise remarked, "Because my performance is overall pretty good. It's not like, the worst." She later noted that "I picture myself as a woman engineer and like, I have to do this ... I see people around me like working ... We're all fighting for this engineering dream. So yeah, that, there's no reason for me to give up."

Denise also derived a sense of social belonging from interactions with her peers. When asked specifically about classroom community and staying connected with peers and to the professor, she noted that, although the physics class did "not feel very united," she drew a sense of belonging from her peers:

So, we were still like exchanging information and stuff. We still remind each other to do homework, to study for the test, and stuff. So, and we are all like, we are all engineering and computer science girls. So, that always motivates me.

Similar to many students we interviewed from this course and other courses, Denise showed a keen sense of resiliency and sustained motivation in the face of relentless changes. Similar to some students, Denise also derived some feelings of belonging from her peers. However, what was unique about Denise was that she specifically mentioned her own performance as a source of belonging in STEM.

\section{Discussion}

We sought to explore whether the use of different online teaching methods supported undergraduate students' engagement and belongingness in their STEM courses at an HSI during the onset of the COVID-19 pandemic. Student surveys and interviews revealed a range of classroom modifications and accommodations determined by faculty to adapt to the transition to online learning. 


\subsection{Teaching Methods That Support Belonging and Engagement}

Surveys of students revealed that non-interactive live lectures negatively predicted their sense of social belonging and interest in STEM, whereas the use of interactive live lectures and breakout groups positively predicted of belonging and positive emotions. That is, instructional strategies that brought students and instructors together in live interactions seemed to boost affective engagement. Interactive live lectures had additional benefits for Hispanic and African American students in supporting their feelings of course belongingness, which was consistent with previous findings [18]. This was corroborated by student interview data suggesting that students highly valued their interactions with other students and faculty, particularly for receiving academic and personal support. Students who had very few means of connecting with the professor or peers were on their own, having to self-study and seek out support independently, and with their efforts for support sometimes thwarted, for example, when instructor office hours were too crowded to meet with them even after waiting for an hour. Other than a resilient few, less interactivity had a negative impact on students' sense of social belonging and engagement in their courses. This was consistent with prior empirical research $[18,42]$ and supported the idea that engaging learning environments were those that enabled interpersonal interaction [19].

Student surveys also revealed that higher reported levels of work to be completed individually were associated with more negative emotions. Although this association was not statistically significant in all statistical models, interview data highlighted that the relationship between negative emotions and individual assignments might partly be explained by students' feelings of stress stemming from the inflexibility of timed assessments delivered virtually, a theme uncovered in interview data. Curiously, we also found that individual work was associated with a greater cognitive engagement and STEM interest overall. One explanation for this is that individual work may have required students to exert more effort, which may have been captured in the cognitive engagement measure. This finding reflects the complex nature of group versus individual work found in the existing literature, showing that the effectiveness of group work is dependent on a host of contextual factors $[18,63,64]$. Future research should investigate why and under what conditions individual work is supportive of student engagement outcomes.

Generally, these findings suggest that individual synchronous practices were associated with greater levels of cognitive engagement and STEM interest. They shed light on practices employed by STEM instructors that positively supported or hindered cognitive and affective engagement and feelings of belonging during the COVID-19 lockdown. Strategies that were especially valued by students of color were (a) interactive lectures, which were associated with greater belonging, and (b) the chat feature, which, based on interview data, seemed to help some women of color feel less judged when asking questions in class.

\subsection{Social Interactions That Support STEM Belonging and Engagement}

In addition to corroborating the quantitative findings, the qualitative findings provided a more in-depth understanding of student experiences of belonging that could be broadly segmented into two types of belonging. Transcripts from group interviews revealed that students experienced feelings of social belonging stemming from connections with peers, professors, and campus communities, and also feelings of competency belonging stemming from prior experiences and interactions.

Social belonging in courses concerns the social interactions that students have with their instructor and their peers as a function of their enrollment in the course. These interactions can lead to friendships, interpersonal connection, and a sense of belonging to a group and becoming part of a wider community. This specifically concerns students' needs for belonging in terms of interpersonal connection and relatedness with other people $[8,22,65]$. This type of belonging seemed to be most supported by synchronous modes of instruction.

Interviews also suggested that, particularly in the asynchronous modes of instruction, competency was implicated as a source of belonging in the course. Yet, this type of 
belonging did not seem related to interpersonal relationships. Rather, if students felt competent based on their positive performance in past STEM courses, they tended to speak about that competency as a basis for belonging in the course. We termed this type of belonging as competency belonging because it specifically concerned whether the student related to the subject matter of the course through their previous experiences of successes. In the terms outlined by the Self-Determination Theory [21,22], relatedness and competency are cast as fundamental psychological needs that facilitate motivation and learning. Our findings supported this theory and provided some emerging evidence that competency can support feelings of relatedness. Needs to feel connected to a larger community need not always happen through live interaction, but can be derived from feelings of mastery and prior performance. These two different sources of course belonging-social belonging and competency belonging-merit more in-depth research.

\subsection{Limitations}

Similar to all studies, our study had several limitations. First, the generalizability of the quantitative findings could have been improved with an increased sample size, along a wider variety of student characteristics. Namely, with greater numbers of students from different ethnicities and racial groups, we might have been able to determine whether identification with specific racial groups might moderate the impacts of instructional practices on belonging rather than using a binary comparison between Hispanic or African American students and other races. For the same reason, we were unable to adjust for classroom clustering effects. However, regression analyses were sufficiently powered for the current analyses. Second, the survey that we used to identify teaching methods may not have captured nuances in how these teaching methods were employed by instructors. For example, breakout groups may have varied in size, activity type, or method for assigning students to groups depending on the course and its instructor. For this reason, we also chose to include a qualitative component to this study to investigate student perceptions of such nuances. Third, there were tradeoffs regarding the size of our group interviews. Due to scheduling conflicts with students, many were only able to meet individually with our interview team, and our group interviews were small groups of one to three. As such, although our data may not have benefitted from the collective synergy of a focusgroup interview of eight to ten students, these smaller interviews provided all students an opportunity to verbally respond at length to every prompt while maintaining our time limits and creating a more intimate environment for students to share personal feelings and impacts from the pandemic.

\subsection{Implications for Practice}

This study has implications for college instructors, students, and policy makers redesigning online learning environments to best support student engagement and close the racial equity gap in STEM. In this section, we share tentative recommendations that follow from our findings.

\subsubsection{Increase Opportunities for Interaction}

Increasing opportunities for synchronous peer-peer and student-faculty interactions may be key for helping students navigate the feelings of isolation and lack of belonging that can result from a purely virtual college experience. Interactive lectures, chat windows, synchronous office hours, and breakout rooms are standard options for online teaching, but our findings suggest that rates of instructor use of these options could be significantly increased. As the benefits of these synchronous and interactive pedagogical methods were strongest among students of color and students with weaker pre-existing friendship networks, these strategies may be especially important for supporting those who face the greatest obstacles to success in STEM. Some of these lessons may also carry over to in-person instruction. For example, some instructors already encouraged their students to use online chat features during in-person instruction to ask questions, which was notable, 
given that several students, especially women of color, reported a greater willingness to participate via chat than in person.

\subsubsection{Incentivize Student-Student Interaction}

Our findings further suggested that asynchronous online teaching was associated with hindered cognitive and affective engagement and feelings of belonging, thereby highlighting the importance of innovating ways for students to meet their academic and social needs in fully asynchronous courses. Perhaps instructors could incentivize students in these sections to interact more with each other, such as by organizing "viewing sessions" to watch pre-recorded lectures together with other students (e.g., over platforms, including Discord or Zoom), thereby encouraging students to chat with each other about the lecture content. Instructors may also consider organizing students into study groups that are incentivized to meet synchronously. Further, qualitative data revealed that students may sometimes feel as if they belong in STEM because they feel competent in their performance on individually assigned exams and homework assignments. Such feelings of competency belonging may partly rely on feelings of personal accomplishment and performance on individual assignments. As such, instructors might consider supporting students' sense of competency by scaffolding learning through feedback, examples, providing clear expectations of learners [66], and normalizing the academic struggle that students inevitably face when learning challenging STEM content [67].

\subsubsection{Be Intentional about How Direct Instruction Is Delivered}

Instructors might consider delivering instruction synchronously only when it involves some level of interactivity. We found that noninteractive synchronous lecturing was associated with lower levels of belonging and interest in STEM, whereas both interactive synchronous and asynchronous lecturing were not. For this reason, we recommend that instructors consider making use of asynchronous lecture methods when no social interaction is necessary, but providing a synchronous lecture when it is.

\subsubsection{Individual Work Is Still Important}

Although synchronous interaction does seem to help satisfy the psychological need to belong, social interaction is not a magic bullet, nor should it be considered the only source of student motivation. We found that individual work was a positive predictor of student cognitive engagement and interest in STEM and marginally predictive of student cognitive engagement, showing that the completion of individual asynchronous assignments may remain an important space for people to privately engage in critical reflection and develop individual interests.

\subsubsection{Incorporate Student Voice}

Finally, our findings stressed the importance of asking students what they need, and what does and does not work in online courses. Although it is common to denigrate online education as an inferior form of instruction, our findings suggested that, under the right conditions, these courses can actively promote student engagement and belonging. As institutions of higher learning continue to decide momentous decisions about future campus technologies and modes of instruction, it is crucial that the voices of teachers and learners are heard.

\section{Conclusions}

Our quantitative findings supported the idea that students, particularly students of color, felt higher course belonging from live human interaction in synchronous courses and more cognitive engagement in asynchronous courses during the virtual transition spurred by the COVID-19 pandemic. Qualitative results highlighted varied types of course belonging (social belonging and competency belonging). Undergraduate STEM instructors 
and administrators who want to improve student engagement in virtual settings might, therefore, consider our central findings that:

- $\quad$ Providing opportunities for classroom interaction can support feelings of social belonging and engagement. We found that students' feelings of social belonging in STEM were related to their interactions with their peers and instructors during breakout groups and discussion, and benefits were pronounced for students of color.

- $\quad$ Students' feelings of competency can serve as the basis for belonginess in STEM. We found that some students explained their feelings of belonging in STEM in terms of their prior experiences of success and sense of competence.

- Individually completed coursework (e.g., exams and quizzes) have tradeoffs. Individual assignments can sometimes be linked to negative student emotions, particularly when strict time limits are imposed. However, they also seem to be important for supporting competency belonging and interest in STEM and may be linked to cognitive engagement.

Overall, these findings have the potential to inform the efforts of university instructors, administrators, and policy makers in helping to optimize instruction in online learning environments.

Supplementary Materials: The following supporting information can be downloaded at: https: / / www.mdpi.com/article/10.3390/educsci12020061/s1, Table S1: Standardized Regression Coefficients for Instructional Practices Predicting Psychological and Cognitive Well-Being with Gender Interactions Included.; All survey materials, interview prompts, and codebooks.

Author Contributions: Conceptualization, I.T., V.S., A.M., N.T.D. and P.B.; methodology, I.T., V.S. and P.B.; formal analysis, I.T.; investigation, I.T.; resources, V.S. and P.B.; writing-original draft preparation, I.T.; writing—review and editing, I.T., V.S., A.M., N.T.D. and P.B.; project administration, V.S. and P.B.; funding acquisition, V.S. and P.B. All authors have read and agreed to the published version of the manuscript.

Funding: This research was funded by the National Science Foundation (NSF-1832405).

Institutional Review Board Statement: The study was conducted in accordance with the Declaration of Helsinki, and approved by the Institutional Review Board (or Ethics Committee) of California State Polytechnic University, Pomona (IRB-20-83, 4-23-2020).

Informed Consent Statement: Informed consent was obtained from all subjects involved in the study.

Data Availability Statement: All survey and interview materials are provided in the Supplemental Materials. The datasets used and analyzed during the current study are available from the corresponding author on reasonable request.

Conflicts of Interest: The authors declare no conflict of interest.

\section{References}

1. UNESCO. COVID-19 Educational Disruption and Response. 2020. Available online: https://en.unesco.org/news/covid-19 -educational-disruption-and-response (accessed on 9 January 2022).

2. Doyle, O. COVID-19: Exacerbating Educational Inequalities? Working Paper. 2020. Available online: http://publicpolicy.ie/ papers / covid-19-exacerbating-educational-inequalities (accessed on 9 January 2022).

3. Kuhfeld, M.; Soland, J.; Tarasawa, B.; Johnson, A.; Ruzek, E.; Liu, J. Projecting the potential impact of COVID-19 school closures on academic achievement. Educ. Res. 2020, 49, 549-565. [CrossRef]

4. Stantcheva, S. Inequalities in the Times of a Pandemic. Economic Policy. 2021. Available online: https://www.economic-policy. org/wp-content/uploads/2021/04/9103_Inequalities-in-the-Times-of-a-Pandemic.pdf (accessed on 9 January 2022).

5. Cobb, P.; Wood, T.; Yackel, E. Discourse, Mathematical Thinking, and Classroom Practice. In Contexts for Learning: Sociocultural Dynamics in Children's Development; Forman, E.A., Minick, N., Stone, C.A., Eds.; Oxford University Press: New York, NY, USA, 1993; pp. 91-119.

6. Nasir, N.I.S.; Hand, V.; Taylor, E.V. Culture and mathematics in school: Boundaries between "cultural" and "domain" knowledge in the mathematics classroom and beyond. Rev. Res. Educ. 2008, 32, 187-240. [CrossRef]

7. Wenger, E. Communities of practice: Learning as a social system. Syst. Think. 1998, 9, 2-3. [CrossRef] 
8. Baumeister, R.F.; Leary, M.R. The need to belong: Desire for interpersonal attachments as a fundamental human motivation. Psychol. Bull. 1995, 117, 497. [CrossRef]

9. Seyranian, V.; Madva, A.; Duong, N.; Abramzon, N.; Tibbetts, Y.; Harackiewicz, J. The longitudinal effects of STEM identity and gender on flourishing and achievement in college physics. Int. J. STEM Educ. 2018, 5, 1-14. [CrossRef] [PubMed]

10. Gutiérrez, R. Introduction: The need to rehumanize mathematics. In Rehumanizing Mathematics for Black, Latinx and Indigenous Students; Gutiérrez, R., Goffney, I., Eds.; National Council of Teachers of Mathematics: Reston, VA, USA, 2018.

11. Johnson, D.R. Campus racial climate perceptions and overall sense of belonging among racially diverse women in STEM majors. J. Coll. Stud. Dev. 2012, 53, 336-346. [CrossRef]

12. Joseph, N.M.; Hailu, M.; Boston, D. Black women's and girls' persistence in the P-20 mathematics pipeline: Two decades of children, youth, and adult Education Research. Rev. Res. Educ. 2017, 41, 203-227. [CrossRef]

13. Good, C.; Rattan, A.; Dweck, C.S. Why do women opt out? Sense of belonging and women's representation in mathematics. J. Personal. Soc. Psychol. 2012, 102, 700-717. [CrossRef]

14. Gray, D.L.L.; Hope, E.C.; Matthews, J.S. Black and belonging at School: A case for interpersonal, instructional, and institutional opportunity structures. Educ. Psychol. 2018, 53, 97-113. [CrossRef]

15. Rainey, K.; Dancy, M.; Mickelson, R.; Stearns, E.; Moller, S. A descriptive study of race and gender differences in how instructional style and perceived professor care influence decisions to major in STEM. Int. J. STEM Educ. 2019, 6, 1-13. [CrossRef]

16. Wilson, D.; Jones, D.; Bocell, F.; Crawford, J.; Kim, M.J.; Veilleux, N.; Plett, M. Belonging and academic engagement among undergraduate STEM students: A multi-institutional study. Res. High. Educ. 2015, 56, 750-776. [CrossRef]

17. Cheryan, S.; Meltzoff, A.N.; Kim, S. Classrooms matter: The design of virtual classrooms influences gender disparities in computer science classes. Comput. Educ. 2011, 57, 1825-1835. [CrossRef]

18. Delahunty, J.; Verenikina, I.; Jones, P. Socio-emotional connections: Identity, belonging and learning in online interactions. A literature review. Technol. Pedagog. Educ. 2014, 23, 243-265. [CrossRef]

19. Kahu, E.R. Framing student engagement in higher education. Stud. High. Educ. 2013, 38, 758-773. [CrossRef]

20. Ryan, R.M.; Deci, E.L. Intrinsic and extrinsic motivation from a self-determination theory perspective: Definitions, theory, practices, and future directions. Contemp. Educ. Psychol. 2020, 61, 101860. [CrossRef]

21. Ryan, R.M.; Deci, E.L. Self-determination theory and the facilitation of intrinsic motivation, social development, and well-being. Am. Psychol. 2000, 55, 68-78. [CrossRef]

22. Ryan, R.M.; Deci, E.L. Intrinsic and extrinsic motivations: Classic definitions and new directions. Contemp. Educ. Psychol. 2000, 25, 54-67. [CrossRef]

23. Pickett, C.L.; Gardner, W.L.; Knowles, M. Getting a cue: The need to belong and enhanced sensitivity to social cues. Personal. Soc. Psychol. Bull. 2004, 30, 1095-1107. [CrossRef]

24. Strayhorn, T.L. College Students' Sense of Belonging: A Key to Educational Success for All Students; Routledge: New York, NY, USA; Oxfordshire, UK, 2018.

25. Leary, M.R.; Cox, C. Belongingness motivation: The mainspring of social action. In Handbook of Motivation Science; Shah, J., Gardner, W., Eds.; Guilford Press: New York, NY, USA, 2007; pp. 27-40.

26. Froiland, J.M.; Worrell, F.C.; Oh, H. Teacher-student relationships, psychological need satisfaction, and happiness among diverse students. Psychol. Sch. 2019, 56, 856-870. [CrossRef]

27. Roorda, D.L.; Koomen, H.M.Y.; Spilt, J.L.; Oort, F.J. The influence of affective teacher-student relationships on students' school engagement and achievement: A meta-analytic approach. Rev. Educ. Res. 2011, 81, 493-529. [CrossRef]

28. Pomerantz, E.M.; Cheung, C.S.; Qin, L. Relatedness between children and parents: Implications for motivation. In Oxford Handbook of Human Motivation; Ryan, R., Ed.; Oxford University Press: New York, NY, USA; Oxford, UK, 2012 ; pp. $335-349$.

29. Anderman, E.M. School effects on psychological outcomes during adolescence. J. Educ. Psychol. 2002, 94, 795. [CrossRef]

30. Cheryan, S.; Ziegler, S.A.; Montoya, A.K. Why are some STEM fields more gender balanced than others? Psychol. Bull. 2017, 143, 1-35. [CrossRef] [PubMed]

31. Cheryan, S.; Plaut, V.C. Explaining underrepresentation: A theory of precluded interest. Sex Roles 2010, 63, 475-488. [CrossRef] [PubMed]

32. Goodenow, C. The psychological sense of school membership among adolescents: Scale development and educational correlates. Psychol. Sch. 1993, 30, 79-90. [CrossRef]

33. Goodenow, C.; Grady, K.E. The relationship of school belonging and friends' values to academic motivation among urban adolescent students. J. Exp. Educ. 1993, 62, 60-71. [CrossRef]

34. Gutman, L.M.; Midgley, C. The role of protective factors in supporting the academic achievement of poor African American students during the middle school transition. J. Youth Adolesc. 2000, 29, 223-249. [CrossRef]

35. Roeser, R.W.; Midgley, C.; Urdan, T.C. Perceptions of the school psychological environment and early adolescents' psychological and behavioral functioning in school: The mediating role of goals and belonging. J. Educ. Psychol. 1996, 88, 408. [CrossRef]

36. Wang, M.; Degol, J.L. Gender gap in Science, Technology, Engineering, and Mathematics (STEM): Current knowledge, implications for practice, policy, and future directions. Educ. Psychol. Rev. 2017, 29, 119-140. [CrossRef]

37. Walton, G.M.; Cohen, G.L. A brief social-belonging intervention improves academic and health outcomes of minority students. Science 2011, 331, 1447-1451. [CrossRef] 
38. Walton, G.M.; Cohen, G.L. A question of belonging: Race, social fit, and achievement. J. Personal. Soc. Psychol. 2007, 92, 82-96. [CrossRef]

39. KewalRamani, A.; Zhang, J.; Wang, X.; Rathbun, A.; Corcoran, L.; Diliberti, M.; Zhang, J. Student Access to Digital Learning Resources Outside of the Classroom (NCES 2017-098). National Center for Education Statistics. 2018. Available online: https:/ / nces.ed.gov/pubsearch/pubsinfo.asp?pubid=2017098 (accessed on 9 January 2022).

40. Bae, C.L.; Lai, M.H. Opportunities to participate in science learning and student engagement: A mixed methods approach to examining person and context factors. J. Educ. Psychol. 2020, 112, 1128. [CrossRef]

41. Fredricks, J.A.; Blumenfeld, P.C.; Paris, A.H. School engagement: Potential of the concept, state of the evidence. Rev. Educ. Res. 2004, 74, 59-109. [CrossRef]

42. Watts, L. Synchronous and asynchronous communication in distance learning a review of the literature. Q. Rev. Distance Educ. 2016, 17, 23-32.

43. Hrastinski, S. Asynchronous and synchronous e-learning. EduCause Q. 2008, 4, 51-55.

44. Jeong, H.; Hmelo-Silver, C.E.; Jo, K. Ten years of computer-supported collaborative learning: A meta-analysis of CSCL in STEM education during 2005-2014. Educ. Res. Rev. 2019, 28, 100-284. [CrossRef]

45. Creswell, J.W. Qualitative Inquiry Research Design: Choosing Among Five Approaches, 2nd ed.; Sage Publications: Thousand Oaks, CA, USA, 2007.

46. Kvale, S.; Brinkmann, S. Interviews: Learning the Craft of Qualitative Research Interviewing, 2nd ed.; Sage Publications: Thousand Oaks, CA, USA, 2009.

47. Geertz, C. Thick description: Toward and interpretive theory of culture. In The Interpretation of Cultures: Selected Essays; Geertz, C., Ed.; Basic Books: New York, NY, USA, 1973; pp. 3-30.

48. Erdfelder, E.; Faul, F.; Buchner, A. GPOWER: A general power analysis program. Behav. Res. Methods Instrum. Comput. 1996, 28, 1-11. [CrossRef]

49. Wieman Group. Background to Online Teaching Surveys. Stanford University. 2020. Available online: http://wiemangroup. stanford.edu/background-online-teaching-surveys-4-10-20 (accessed on 9 January 2022).

50. Conway, L.G., III; Woodard, S.R.; Zubrod, A. Social Psychological Measurements of COVID-19: Coronavirus Perceived Threat, Government Response, Impacts, and Experiences Questionnaires. 2020. Available online: https://psyarxiv.com/z2x9a (accessed on 9 January 2022).

51. Fredrickson, B.L.; Tugade, M.M.; Waugh, C.E.; Larkin, G.R. What good are positive emotions in crisis? A prospective study of resilience and emotions following the terrorist attacks on the United States on September 11th, 2001. J. Personal. Soc. Psychol. 2003, 84, 365-376. [CrossRef]

52. Hulleman, C.S.; Godes, O.; Hendricks, B.L.; Harackiewicz, J.M. Enhancing interest and performance with a utility value intervention. J. Educ. Psychol. 2010, 102, 880-895. [CrossRef]

53. Greene, B.A.; Miller, R.B. Influences on achievement: Goals, perceived ability, and cognitive engagement. Contemp. Educ. Psychol. 1996, 21, 181-192. [CrossRef]

54. Barnes, D.C.; Engelland, B.T.; Matherne, C.F.; Martin, W.C.; Orgeron, C.P.; Ring, J.K.; Williams, Z. Developing a psychometrically sound measure of collegiate teaching proficiency. Coll. Stud. J. 2008, 42, 199-214.

55. McLafferty, I. Focus group interviews as a data collecting strategy. J. Adv. Nurs. 2004, 48, 187-194. [CrossRef] [PubMed]

56. Patton, M.Q. Qualitative Research and Evaluation Methods, 4th ed.; Sage Publications: Thousand Oaks, CA, USA, 2014.

57. Tabachnick, B.G.; Fidell, L.S. Using Multivariate Statistics, 6th ed.; Pearson: New York, NY, USA, 2013.

58. Saladaña, J. The Coding Manual for Qualitative Researchers, 3rd ed.; Sage Publication: Thousand Oaks, CA, USA, 2015.

59. Yin, R.K. Case Study Research: Design and Methods, 3rd ed.; Sage Publications: Thousand Oaks, CA, USA, 2003.

60. Yin, R.K. Applications of Case Study Research, 3rd ed.; Sage Publications: Thousand Oaks, CA, USA, 2012.

61. Scholz, R.W.; Tietje, O. Embedded Case Study Methods: Integrating Quantitative and Qualitative Knowledge; Sage Publications: Thousand Oaks, CA, USA, 2002.

62. Stake, R.E. Qualitative case studies. In The Sage Handbook of Qualitative Research, 3rd ed.; Denzin, N.K., Lincoln, Y.S., Eds.; Sage Publications: Thousand Oaks, CA, USA, 2005.

63. Guerin, B. Social facilitation. In The Corsini Encyclopedia of Psychology; Weiner, I.B., Craighead, W.E., Eds.; John Wiley \& Sons, Inc.: Hoboken, NJ, USA, 2010.

64. Micari, M.; Pazos, P.; Streitwieser, B.; Light, G. Small-group learning in undergraduate STEM disciplines: Effect of group type on student achievement. Educ. Res. Eval. 2010, 16, 269-286. [CrossRef]

65. Deci, E.L.; Vallerand, R.J.; Pelletier, L.G.; Ryan, R.M. Motivation and education: The self-determination perspective. Educ. Psychol. 1991, 26, 325-346. [CrossRef]

66. McLoughlin, C.; Marchall, L. Scaffolding: A Model for Learner Support in an Online Teaching Environment. In Proceedings of the 9th Annual Teaching Learning Forum, Perth, Australia, Curtain University of Technology, Perth, Australia, 2-4 February 2000; Herrmann, A., Kulski, M.M., Eds. Available online: https:/ /litec.curtin.edu.au/events/conferences/tlf/tlf2000/mcloughlin2 html (accessed on 9 January 2022).

67. Lin-Siegler, X.; Ahn, J.N.; Chen, J.; Fang, F.F.A.; Luna-Lucero, M. Even Einstein struggled: Effects of learning about great scientists' struggles on high school students' motivation to learn science. J. Educ. Psychol. 2016, 108, 314. [CrossRef] 